\title{
Prevalence and determinants of under-nutrition among children under six: a cross-sectional survey in Fars province, Iran
}

\author{
Elham Kavosi ${ }^{1}$, Zahra Hassanzadeh Rostami ${ }^{1, *}, Z^{*}$ ahra Kavosi ${ }^{1}$, Aliasghar Nasihatkon ${ }^{2}$, Mohsen Moghadami ${ }^{3}$, \\ Mohammadreza Heidari ${ }^{1}$
}

\begin{abstract}
Background: Childhood malnutrition as a major public health problem among children in developing countries can affect physical and intellectual growth and is also considered as a main cause of child morbidity and mortality. The objective of this study was to estimate the prevalence of under-nutrition and identify determinants of malnutrition among children under 6 years of age in Fars province, Iran.

Methods: This survey was conducted by house to house visit through multi-stage sampling in 30 cities of Fars province, during December 2012 to January 2013. A total of 15408 children, aged 0-6 years old, were studied for nutritional assessment in terms of underweight, stunting, and wasting. Also, socio-demographic measures were obtained from structured questionnaire. Backward stepwise logistic regression was used to relate underlying factors to the odds of under-nutrition indices.

Results: The rates of stunting, underweight, and wasting were $9.53,9.66$, and $8.19 \%$, respectively. Male children were more stunted compared to females $(\mathrm{OR}=1.41, \mathrm{CI}: 1.26-1.58)$. Also, stunting was significantly associated with lower family income $(\mathrm{OR}=3.21, \mathrm{CI}: 1.17-8.85)$ and lower maternal education ( $\mathrm{OR}=0.80, \mathrm{CI}$ : 0.64-0.98). Living in urban areas, and poor water supply were identified as significant risk factors of all three types of childhood under-nutrition. Moreover, Khamse and Arab ethnic groups were more vulnerable to under-nutrition. There was a suggestion that non-access to health services were associated with wasting (OR=1.87, CI: 1.39-2.52) and also large family size was related to underweight $(\mathrm{OR}=1.35$, CI: $1.10-1.65)$.

Conclusion: The prevalence of under-nutrition in the study population was categorized in low levels. However, planning the public preventive strategies can help to control childhood under-nutrition according to underlying factors of malnutrition in the study population including gender, settlement area, family size, ethnicity, family income, maternal education, health services, and also safe water supply.

Keywords: Children, Prevalence, Malnutrition, Stunting, Underweight, Wasting

Copyright: (C) 2014 by Kerman University of Medical Sciences

Citation: Kavosi E, Hassanzadeh Rostami Z, Kavosi Z, Nasihatkon A, Moghadami M, Heidari M. Prevalence and determinants of under-nutrition among children under six: a cross-sectional survey in Fars province, Iran. Int $J$ Health Policy Manag 2014; 3: 71-76. doi: 10.15171/ijhpm.2014.63
\end{abstract}

Article History:

Received: 15 April 2014 Accepted: 18 July 2014 ePublished: 24 July 2014

*Correspondence to: Zahra Hassanzadeh Rostami Email: hassanzadeh_z8@yahoo.com

\section{Introduction}

Malnutrition, as the main cause of morbidity and mortality in infants and children under five years of age, accounts for at least half of all childhood death worldwide $(1,2)$. Also it is recognized as the underlying cause of related deaths of childhood disease such as measles, diarrhea, and acute respiratory infectious diseases $(1,2)$. Studies have reported that despite the economic development, childhood malnutrition still remains a significant public health problem in developing countries $(1,3,4)$. In general, the nutritional status of preschool children, as the most vulnerable age group, can be used as an indicator of health and nutrition of community (3). Consequences of childhood undernutrition have been explained as growth failure, impaired intellectual and physical development, lower resistances to infection and high incidence rate of some chronic disease (1). Besides, it affects human performance and decreases the population survival, also it may enhance the economic burden $(3,5)$. Several determinants contribute to childhood malnutrition including intra-uterine growth retardation, low birth weight, inadequate exclusive breast feeding, unsuitable complementary feeding, maternal literacy, low nutritional knowledge, insufficient energy and micronutrient intake, birth spacing, birth rank, socio-economic background, food availability, housing, health services, vaccination, infectious disease, etc. $(4,5)$.

The nutritional status of children can be evaluated by their growth. Under-nutrition, as one form of malnutrition, has been measured by anthropometric indicators including stunting, wasting, and underweight. Stunting (low height for age) and wasting (low weight for height) are respectively associated with chronic malnutrition and current nutritional status. Underweight (low weight for age) represents both chronic and acute malnutrition (6). Globally, the prevalence of stunting, underweight and wasting in children under-five years are 26,16 , and $8 \%$, respectively. These figures in Asia are $26.8,19.3$, and $10.1 \%$, respectively (7). Several studies have been conducted in Iran in recent years, representing revolution in malnutrition with improved health services, sanitation, immunization, and knowledge. The rate of stunting, underweight and wasting in Iranian children under-five years have been reported to be $13.1,7.6$, and $4.5 \%$, 
respectively in 2000-2002 (8).

Nowadays with change in lifestyle and occurrence of nutrition transition, disease model and nutritional status of community have been changed. However, malnutrition remains as serious nutritional problem in Iran. So the rate of under-nutrition and its determinants maybe changed recent years. On the other hand, with the report of a national survey: Food Security Information and Mapping System in Iran, Fars province was shown as moderately food insecure rank (9). Therefore, measuring the risk factors can be helpful in control of malnutrition and also improve health development. Moreover, there was no comprehensive study in Fars province to evaluate nutritional status of children. So given the serious consequence of under-nutrition and lack of studies which investigate its rate in Fars province, we conducted the present study to assess the prevalence of under-nutrition and determine the major contributing factors of under-nutrition among children under 6 years.

\section{Methods}

This cross-sectional community-based survey was conducted in urban and rural areas of Fars province during December 2012 to January 2013. Participants were 15408 children under-6-years of age selected through door-to-door visits using cluster and multi-stage sampling. The sampling was conducted in all 30 cities of Fars province. Cities were divided in 16 big and 15 small cities and sampling was performed in urban and rural areas of each city by clustering. One city divided in 2 big cities because of its large population. Then according to $22 \%$ predicted prevalence of under-nutrition, $95 \%$ confidence interval and $\pm 5 \%$ error and using the formula $\mathrm{n}=\mathrm{Nz}^{2} \mathrm{pq} / \mathrm{d}^{2}(\mathrm{~N}-1)+\mathrm{z}^{2} \mathrm{pq}$, and also with usage of finite population correction factor, the sample size was estimated respectively 264 and 232 cases for big and small cities. Finally, with assuming a design effect equal to 2 , total sample size was obtained 15408.

The parents or child legal guardian were informed about the study goals and verbal consent was obtained to take their child's anthropometric measurements. Inclusion criteria were healthy children aged 0-6 years, and children who had infection, metabolic, congenital, and chronic diseases were excluded from the study.

Two types of instruments were used: a structured questionnaire and anthropometric measurements including weight and height. Weight was recorded while the subjects were minimally clothed using a digital weighing scale (Seca, Germany) with $0.10 \mathrm{~kg}$ accuracy. Height and length were measured with bare foot using measuring board for babies and toddlers (Seca, Germany) with $0.10 \mathrm{~cm}$ accuracy by trained health services staff. The questionnaire included information about child age and gender, child birth weight (recorded from the child health report card), birth order, number of younger siblings, family size, child care-giver, household head, parental education and occupation, family income (categorized in five groups; <134, 134-200, 201-334, 335-667 and >667 US dollars), house meter, residence region of city, type of settlement, religion, ethnicity, health services usage, access to safe water supply, and household facilities and furniture including access to freezer, washing machine, dish washing machine, microwave, computer, cell phone, and personal car.

Anthropometric indices including stunting, underweight, and wasting were respectively defined as height for age, weight for age, and weight for height at least 2 standard deviations below the mean for children aged 0-5 according to reference growth charts from the National Center for Health Statistics (NCHS)/Center for Disease Control and Prevention (CDC) (2000) (10).

\section{Statistical analysis}

The Epi-Info software program, version 2008 for Windows was used to determine anthropometric indices. Data were analyzed using SPSS software version 16 for Windows (SPSS Inc., Chicago, USA). The numerical data were presented as mean \pm SD and categorical variables were presented as $\mathrm{N}(\%)$. Backward stepwise logistic regression analyses were used to relate socio-economic and demographic factors on the under-nutrition indices, and the results were presented by Odds Ratios (ORs) with 95\% Confidence Interval (CI). The significance level was set at $P<0.05$ in all statistical tests.

\section{Results}

A total of 15408 children under 6 years of age participated in the study. Of them, 15278 children including 8013 boys and 7265 girls were used in the final analyses. Demographic and socio-economic characteristics of the study subjects are shown in Table 1. The overall prevalence of stunting, underweight and wasting were $9.53,9.66$, and $8.19 \%$, respectively.

Table 2 reported the determinants of stunting. The OR of stunting in boys was 1.41 relative to girls. Also, children who settled in urban areas were significantly more likely to be stunted as compared to those of rural areas $(\mathrm{OR}=1.23$, CI: 1.08-1.40). Higher family income was determined as the protective factor of stunting. Children in family with an income higher than 667 US dollars were significantly less likely to be stunted compared to those with an income of 334 US dollars and lower. Moreover, maternal education in diploma and lower was determined as stunting risk factors as compared to universal education. Children whose ethnicity was Khamse showed increased risk of stunting compared to Fars ethnicity $(\mathrm{OR}=3.36$, CI: 1.62-6.93). Besides, lack of safe water supply was another predictor of stunting $(\mathrm{OR}=1.27$, CI: $0.98-1.66)$.

Children who resided in urban areas were found to have significantly 1.33 times increased risk of underweight compared to those living in rural area. Khamse and Arab ethnic minorities were respectively about 1.95 and 1.48 times more related to underweight than those of Fars ethnicity. Two other significant predictors of underweight were nonsafe water supply and large family size since children in households with more than 4 members were 1.35 times more likely to be underweight relative to $1-4$ members.

The OR of wasting in urban area was 1.25 relative to rural areas. The lower than 667 US dollars family income was known as wasting risk factor relative to higher than 667 US dollars. The most predictor of wasting was Arab ethnic minority whose 
Table 1. Demographic and socio-economic characteristics of the study subjects $(n=15278)$

\begin{tabular}{|c|c|c|}
\hline Characteristic & $\mathbf{N}$ & $\%$ \\
\hline \multicolumn{3}{|l|}{ Child's gender } \\
\hline Male & 8013 & 52.45 \\
\hline Female & 7265 & 47.55 \\
\hline \multicolumn{3}{|l|}{ Birth order } \\
\hline $1 s t$ & 8327 & 54.63 \\
\hline 2nd & 4589 & 30.11 \\
\hline $3 r d$ & 1540 & 10.10 \\
\hline 4th & 517 & 3.39 \\
\hline 5 th + & 269 & 1.77 \\
\hline \multicolumn{3}{|l|}{ Family size } \\
\hline $1-4$ & 11199 & 73.34 \\
\hline$>4$ & 4070 & 26.66 \\
\hline \multicolumn{3}{|l|}{ Younger siblings } \\
\hline 1 Younger siblings & 10897 & 71.43 \\
\hline 2 Younger siblings & 4057 & 26.60 \\
\hline $3+$ Younger siblings & 301 & 1.97 \\
\hline \multicolumn{3}{|l|}{ Who care the child } \\
\hline Mother & 15122 & 98.93 \\
\hline Others & 163 & 1.07 \\
\hline \multicolumn{3}{|l|}{ Household head } \\
\hline Father & 15039 & 98.49 \\
\hline Mother & 146 & 0.95 \\
\hline Others & 85 & 0.56 \\
\hline \multicolumn{3}{|l|}{ Mother's education } \\
\hline Lower than diploma & 8694 & 56.89 \\
\hline Diploma & 4447 & 29.10 \\
\hline Universal education & 2142 & 14.01 \\
\hline \multicolumn{3}{|l|}{ Father's education } \\
\hline Lower than diploma & 9114 & 59.86 \\
\hline Diploma & 3960 & 26.01 \\
\hline Universal education & 2152 & 14.13 \\
\hline \multicolumn{3}{|c|}{ Residence region of city } \\
\hline North & 2029 & 25.24 \\
\hline South & 1901 & 23.65 \\
\hline Center & 3097 & 38.52 \\
\hline Outskirt & 1012 & 12.59 \\
\hline \multicolumn{3}{|l|}{ Type of settlement } \\
\hline Urban & 8028 & 52.50 \\
\hline Rural & 7262 & 47.50 \\
\hline \multicolumn{3}{|l|}{ Ethnicity } \\
\hline Fars & 12612 & 82.52 \\
\hline Ghashghaei & 925 & 6.05 \\
\hline Khamse & 48 & 0.32 \\
\hline Mamasani & 1047 & 6.85 \\
\hline Arab & 205 & 1.34 \\
\hline Other & 446 & 2.92 \\
\hline \multicolumn{3}{|l|}{ Religion } \\
\hline Islam & 15265 & 99.88 \\
\hline Others & 18 & 0.12 \\
\hline \multicolumn{3}{|l|}{ Health services } \\
\hline Yes & 14848 & 97.27 \\
\hline No & 417 & 2.73 \\
\hline \multicolumn{3}{|l|}{ Access of safe water } \\
\hline Yes & 14618 & 95.79 \\
\hline No & 642 & 4.21 \\
\hline \multicolumn{3}{|l|}{ Family income } \\
\hline$<134$ US dollars & 5698 & 37.32 \\
\hline 134-200 US dollars & 5833 & 38.21 \\
\hline 201-334 US dollars & 2856 & 18.71 \\
\hline 335-667 US dollars & 751 & 4.92 \\
\hline >667 US dollars & 129 & 0.84 \\
\hline
\end{tabular}

children were 2.58 times more likely to be wasted $(\mathrm{OR}=2.58$, CI: 1.75-3.80). The OR of wasting in children who did not get health services was 1.87 relative to others. Unsafe water supply was also seen as a significant wasting risk factor $(\mathrm{OR}=1.58$, CI: $1.21-2.05)$.

\section{Discussion}

The first goal of The Eight Millennium Development Goals (MDGs) is to eradicate extreme poverty and hunger. And the third target of this goal is to halve the proportion of people suffering from hunger up to 2015. But based on the MDG Report 2013, still one in eight people worldwide does not consume enough food on a regular basis to gain their minimum dietary energy requirements and the majority of the under-nourished ones (852 million) reside in developing countries (11).

The present study assessed the prevalence and also underlying factors of under-nutrition among children under-six years of age. The prevalence of stunting, underweight, and wasting in our study was estimated 9.53, 9.66, and $8.19 \%$ respectively. According to World Health Organization (WHO) category, the study subjects were in the lower level of stunting and underweight and medium level of wasting (12). The 1998 Anthropometric Nutritional Indicators Survey (ANIS) conducted on Iranian preschool children has reported 15.3, 10.8 , and $4.9 \%$ for stunting, underweight, and wasting, respectively, and these rates in Fars province were 16.7, 11.3, and $5.9 \%(13)$. Several studies in various regions and provinces of Iran reported different rates of malnutrition which depends on various developmental conditions of that region. For example, the rate of stunting, underweight and wasting in Zahedan and South-Khorasan province was higher than the national rates and it has been respectively reported 25.5, 17.3, 6.8\% and 16.6, 12.9, 7.5\% (14,15). Moreover, Findings demonstrated reducing rate of under-nutrition during last years that can be explained by increase in educational level, nutritional knowledge, developing healthcare services, and increased family income.

The prevalence of under-nutrition in our study was nearly consistent with those reported by de Souza et al. (16) and Zhang et al. (17). They reported stunting and wasting 9.9 and $4.1 \%$ respectively in Brazil and also 3.07\% wasting and 7.19\% underweight in China $(16,17)$. In general, different prevalence of under-nutrition in various parts of the world ranged about $5 \%$ to $40 \%$ with different risk factors categorized as child or family characteristics, socio-economic status, healthcare, and prevalent infectious disease $(1,5,18)$.

The regression model demonstrated child's gender, type of settlement, family income, maternal education, ethnicity, and health water supply as risk factors of stunting. Moreover, risk factor of underweight was child's gender, type of settlement, family size, ethnicity, and health water supply. Finally, type of settlement, family income, ethnicity, health services, and health water supply known as wasting risk factors.

The results showed higher prevalence of stunting malnutrition in male children compared to females; however, underweight and wasting were not significantly associated with gender. Male children are more vulnerable to early childhood disease 


\section{Table 1. Continued}

\begin{tabular}{|c|c|c|}
\hline \multicolumn{3}{|l|}{ Access of house facilities and furniture } \\
\hline 0 item (access to non-facilities and furniture) & 225 & 1.47 \\
\hline $\begin{array}{l}1 \text { item (access to } 1 \text { item of determined facilities } \\
\text { and furniture) }\end{array}$ & 880 & 5.77 \\
\hline $\begin{array}{l}2 \text { item (access to } 2 \text { item of determined facilities } \\
\text { and furniture) }\end{array}$ & 2155 & 14.14 \\
\hline $\begin{array}{l}3 \text { item (access to } 3 \text { item of determined facilities } \\
\text { and furniture) }\end{array}$ & 3324 & 21.81 \\
\hline $\begin{array}{l}4 \text { item (access to } 4 \text { item of determined facilities } \\
\text { and furniture) }\end{array}$ & 3845 & 25.22 \\
\hline $\begin{array}{l}5 \text { item (access to } 5 \text { item of determined facilities } \\
\text { and furniture) }\end{array}$ & 3135 & 20.57 \\
\hline $\begin{array}{l}6 \text { item (access to } 6 \text { item of determined facilities } \\
\text { and furniture) }\end{array}$ & 1478 & 9.70 \\
\hline $\begin{array}{l}7 \text { item (access to all } 7 \text { item of determined facilities } \\
\text { and furniture) }\end{array}$ & 201 & 1.32 \\
\hline \multicolumn{3}{|l|}{ Father's occupation } \\
\hline Unemployed & 490 & 3.22 \\
\hline Farmer & 2003 & 13.16 \\
\hline Worker & 3349 & 22.00 \\
\hline Employee & 2252 & 14.79 \\
\hline Retired & 136 & 0.89 \\
\hline Other (Business, etc.) & 6993 & 45.94 \\
\hline \multicolumn{3}{|l|}{ Mother's occupation } \\
\hline Housewife & 14137 & 92.53 \\
\hline Working mothers & 1142 & 7.47 \\
\hline Birth weight* & \multicolumn{2}{|c|}{$3133.40 \pm 496.72$} \\
\hline House meter* & \multicolumn{2}{|c|}{$131.44 \pm 127.23$} \\
\hline
\end{tabular}

${ }^{*}$ Data are presented as mean \pm SD.

and health problem. This finding was supported by other research which introduced male gender as a risk factor of malnutrition $(1,2,17,19)$.

The present study noticed urbanization as a main determinant of all three types of under-nutrition. Children who settled in urban areas were respectively 1.23, 1.33, and 1.25 times more stunted, underweighted, and wasted compared to rural area. Janevic et al. and Shibulal et al. $(6,18)$ stated the same result; however, several studies reported the opposite (19), explaining that high prevalence of under-nutrition in rural areas may be the result of low educational level, low social rank, poor water supply, and high incidence of infectious disease. Now, the rapid urbanization and also high poverty and hunger that influence health and nutrition especially for children, are suggested as the probable causes of high rate of malnutrition in urban population (20).

We found that large family size can significantly increase the risk of childhood underweight with 1.35 odds ratio. As shown in previous research, children in crowded families are more susceptible to malnutrition $(2,19,21)$. Food intake and accessibility of healthcare decrease with higher family size especially in low income families.

Our findings have revealed the association of the family income lower than 667 US dollars with stunting and wasting. A study by Janevic et al. reported the amount of family income as an important determinant of chronic malnutrition (6). This significant association may be due to high quality of life, giving essential health services and also adequate dietary intake. Moreover, low literacy and low purchasing capacity, and also poor sanitation and hygiene are common results of economic inequality.
Previous studies reported the higher prevalence of undernutrition in families with lower educational level. In agreement, this study showed the lower risk of stunting in children whose mothers have university education as compared to those with diploma and lower. As educated mothers have enough knowledge about their children's health and nutrition, the nutritional status of children can be developed through improvement of child care, health services usage, hygiene and sanitation, etc. Demissie et al., Jesmin et al., Janevic et al., and Shibulal et al. reported the same results $(1,5,6,18)$. Moreover, the father's education can influence the child's health and nutritional status, because of its role in family income and his decision in family food buying basket $(5,16,21)$. However, we did not find a significant relation between children's nutritional status and father's education. Ethnic minorities showed a significant association with all three types of under-nutrition. Among ethnic groups in Fars province, Khamse and Arab are the most vulnerable group to under-nutrition. Likewise, previous studies have found that ethnicity can affect nutritional status $(22,23)$. Different traditional cultures in various ethnic groups exist with different patterns of food consumption, food habits, living condition, and other environmental factors (24).

Among the study population, children who have access to health services were at lower risk of wasting. Similarly, Kabubo-Mariara et al. (25) indicated that health services positively correlated with the height of preschool children. This result has an important message for policy-makers that provide health service facility and make financial and geographical access to health services; they can help reduce under-nutrition.

Another determinant of all three types of under-nutrition was poor water supply. Taking this point into account, several researchers have shown piped water as a protective factor of malnutrition $(1,26)$. Safe water prevents the progression of water born diseases which together with sanitation and hygiene can negatively affect health and nutritional status and promotion of chronic malnutrition (27).

Other variables assessed in present study were parental occupation, birth weight, and birth order. Although previous studies reported the association of these factors to undernutrition $(1,5,16,18)$, our results did not find them in undernutrition pattern.

\section{Limitations}

The limitation of this study was non-suitable cooperation of child care-givers in sampling and child selection. The nontruly statement of subjects in response to some questions such as family income which may cause bias was another limitation. However, we reduce this probably bias with attention to father's occupation. Moreover, the lack of standard weight scales limited the reviewers. So they obliged to transfer weight scales from one city to another and this was lengthed the study duration.

\section{Conclusion}

Despite the decreased trend of under-nutrition in the last years, still malnutrition in young children must be considered 
Table 2. Logistic regression analysis of significant determinants related to stunting, underweight, and wasting among under-six years children

\begin{tabular}{|c|c|c|c|}
\hline Parameters & $\begin{array}{c}\text { Stunting } \\
\text { OR }(95 \% \mathrm{Cl})\end{array}$ & $\begin{array}{c}\text { Underweight } \\
\text { OR }(95 \% \mathrm{Cl})\end{array}$ & $\begin{array}{c}\text { Wasting } \\
\text { OR }(95 \% \mathrm{Cl})\end{array}$ \\
\hline \multicolumn{4}{|l|}{ Child's gender } \\
\hline Male & $1.41(1.26-1.58)$ & $1.10(0.99-1.24)$ & $*$ \\
\hline \multicolumn{4}{|l|}{ Female (Ref) } \\
\hline \multicolumn{4}{|l|}{ Type of settlement } \\
\hline Urban & $1.23(1.08-1.40)$ & $1.33(1.18-1.50)$ & $1.25(1.10-1.42)$ \\
\hline \multicolumn{4}{|l|}{ Rural (Ref) } \\
\hline \multicolumn{4}{|l|}{ Family size } \\
\hline 1-4 (Ref) & $*$ & & $*$ \\
\hline$>4$ & & $1.35(1.10-1.65)$ & \\
\hline \multicolumn{4}{|l|}{ Family income } \\
\hline$<134$ dollar & $3.21(1.17-8.85)$ & & $1.81(0.83-3.93)$ \\
\hline 134-200 dollar & 3.66 (1.33-10.04) & & $1.53(0.71-3.33)$ \\
\hline 201-334 dollar & $3.18(1.15-8.75)$ & $*$ & $1.42(0.65-3.11)$ \\
\hline \multicolumn{4}{|l|}{ >667 dollar (Ref) } \\
\hline \multicolumn{4}{|l|}{ Maternal education } \\
\hline Diploma and lower & $0.80(0.64-0.98)$ & & \\
\hline Diploma & $0.72(0.59-0.89)$ & $*$ & $*$ \\
\hline \multicolumn{4}{|c|}{ Universal education (Ref) } \\
\hline \multicolumn{4}{|l|}{ Ethnicity } \\
\hline \multicolumn{4}{|l|}{ Fars (Ref) } \\
\hline Ghashghaei & $0.90(0.70-1.15)$ & $0.89(0.70-1.14)$ & $1.24(0.98-1.57)$ \\
\hline Khamse & $3.36(1.62-6.93)$ & $1.95(0.85-4.48)$ & $0.57(0.13-2.38)$ \\
\hline Mamasani & $0.99(0.79-1.24)$ & $0.60(0.46-0.78)$ & $0.65(0.49-0.86)$ \\
\hline Arab & $0.87(0.51-1.49)$ & $1.48(0.96-2.29)$ & $2.58(1.75-3.80)$ \\
\hline Others & $1.58(1.19-2.11)$ & $1.61(1.21-2.14)$ & $1.00(0.70-1.43)$ \\
\hline \multicolumn{4}{|l|}{ Health services } \\
\hline \multicolumn{4}{|l|}{ Health water supply } \\
\hline \multicolumn{4}{|l|}{ Yes (Ref.) } \\
\hline No & $1.27(0.98-1.66)$ & $1.37(1.06-1.76)$ & $1.58(1.21-2.05)$ \\
\hline
\end{tabular}

* Variable not determined as stunting, underweight, and wasting in backward stepwise logistic regression models, Ref; Reference category

as a public problem because of its major effect on morbidity and mortality of children and impairment of intellectual and physical development in long-term. Our study specially demonstrated child's gender, type of residence, family size, family income, maternal education, ethnicity, health services, and safe water supply as contributing factors to childhood malnutrition in the study population. So, there is a need to plan strategies and preventive public policies based on these regional specific risk factors to alleviate early malnutrition.

\section{Acknowledgments}

This article was financially supported by social determinants of health research center, Shiraz University of Medical Sciences, Shiraz, Iran. We are grateful to the health services staff in Fars province for cooperating in interview and data collection. Also we thank parents and child care-givers.

\section{Ethical issues}

This study was approved by the ethic committee of Shiraz University of Medical Sciences. Ethical principles were adhered to throughout the research. These included informing all child legal guardians and obtaining verbal consent.

Competing interests

The authors declare that they have no competing interests.
Authors' contributions

EK carried out the design and all the experiments, participated in data acquisition and data analysis. ZH carried out the design, participated in data analysis and prepared the manuscript. ZK provided assistance in the design of the study, and edited the manuscript. AN analyzed the data and edited the manuscript. MM provided assistance in the design of the study, and coordinated in all the experiments. $\mathrm{MH}$ provided assistance in the design of the study, and coordinated in all the experiments. All authors have read and approved the content of the manuscript.

\section{Authors' affiliations}

${ }^{1}$ Social Determinants of Health Research Center, Shiraz University of Medical Sciences, Shiraz, Iran. 'Fars Petroleum Industry Health Organization, Fars, Iran. ${ }^{3}$ Department of Internal Medicine, Social Determinants of Health Research Center, Shiraz University of Medical Sciences, Shiraz, Iran.

\section{References}

1. Demissie S, Worku A. Magnitude and Factors Associated with Malnutrition in Children 6-59 Months of Age in Pastoral Community of Dollo Ado District, Somali Region, Ethiopia. Sci J Public Health 2013; 1: 175-83. doi: 10.11648/j.sjph.20130104.12

2. Meshram II, Arlappa N, Balakrishna N, Rao KM, Laxmaiah A, Brahmam GNV. Trends in the prevalence of undernutrition, nutrient and food intake and predictors of undernutrition among under five year tribal children in India. Asia Pac J Clin Nutr 2012; 21: 568-76.

3. Masibo PK, Makoka D. Trends and determinants of undernutrition among young Kenyan children: Kenya Demographic and Health Survey; 1993, 1998, 2003 and 2008-2009. Public Health Nutr 


\section{2; 15: 1715-27. doi: 10.1017/s1368980012002856}

4. Pasricha SR, Biggs BA. Undernutrition among children in South and South-East Asia. J Paediatr Child Health 2010; 46: 497503. doi: 10.1111/j.1440-1754.2010.01839.x

5. Jesmin A, Yamamoto SS, Malik AA, Haque A. Prevalence and determinants of chronic malnutrition among preschool children: a cross-sectional study in Dhaka City, Bangladesh. J Health Popul Nutr 2011; 29: 494-9. doi: 10.3329/jhpn.v29i5.8903

6. Janevic T, Petrovic O, Bjelic I, Kubera A. Risk factors for childhood malnutrition in Roma settlements in Serbia. BMC Public Health 2010; 10: 1-8. doi: 10.1186/1471-2458-10-509

7. United Nations Children's Fund, World Health Organization, The World Bank. UNICEF WHO-World Bank Joint Child Malnutrition Estimates. New York, Geneva, Washington DC: UNICEF, WHO, The World Bank; 2012.

8. Houshyarrad A, Dorosti Motlagh AR, Kalantari N, Abd Elahi M, Abtahi M. Prevalence of stunting, underweight, wasting and overweight among iranian under-five-year-old children (20002002). Journal of Nutrition Sciences \& Food Technology 2009; 3: 49-56.

9. Kolahdooz F, Najafi F. Report of a national survey: Food Security Information and Mapping System in Iran. Tehran: Ministry of Health and Medical Education; 2012.

10. Kuczmarski RJ, Ogden CL, Guo SS, Grummer-Strawn LM, Flegal KM, Mei Z, et al. 2000 CDC growth charts for the United States: Methods and development. Vital Health Stat 11 2002; 246: 1-190.

11. UN Department of Economic and Social Affairs. The Millennium Development Goals Report 2013 [internet]. Available from: https://www.unfpa.org/public/publications/pid/6090

12. [No authors listed]. Physical status: the use and interpretation of anthropometry. Report of a WHO Expert Committee. World Health Organ Tech Rep Ser 1995; 854: 1-452.

13. The nutritional status of children, October-November 1998 (ANIS). Teheran: Ministry of Health and Medical Education and UNICEF; 2000.

14. Sheykhi M, EftekhariNia M, Hadipour M, Esmaillzadeh A. Prevalence of Stunting, Underweight and Wasting According to National Center for Health Statistics Criteria in Rural Children under 6 in Zahedan, Iran, in 2010. J Health Syst Res 2013; 9: 153-8.

15. Sharifzadeh GR, Mehrjoofard H, Raghebi S. Prevalence of Malnutrition in under 6-year Olds in South Khorasan, Iran. Iran J Pediatr 2010; 20: 435-41.

16. de Souza OF, Benício MH, de Castro TG, Muniz PT, Cardoso
MA. Malnutrition among children under 60 months of age in two cities of the state of Acre, Brazil: prevalence and associated factors. Rev Bras Epidemiol 2012; 15: 211-21.

17. Zhang J, Shi J, Himes JH, Du Y, Yang S, Shi S, et al. Undernutrition status of children under 5 years in Chinese rural areas - data from the National Rural Children Growth Standard Survey, 2006. Asia Pac J Clin Nutr 2011; 20: 584-92.

18. Shibulal A. A study on the prevalence of under-nutrition and its determinants in anganwadi children of Malappuram district, Kerala. Trivandrum, Achutha Menon Centre for Health Science Studies, Sree Chitra Tirunal Institute for Medical Sciences and Technology, Working Paper no. 10, 2013.

19. Hien NN, Kam S. Nutritional status and the characteristics related to malnutrition in children under five years of age in Nghean, Vietnam. J Prev Med Public Health 2008; 41: 232-40. doi: $\quad$ 10.3961/jpmph.2008.41.4.232

20. Ghosh S, Shah D. Nutritional problems in urban slum children. Indian Pediatr 2004; 41: 682-96.

21. Mahyar A, Ayazi P, Fallahi M, Javadi THS, Farkhondehmehr $B$, Javadi A, et al. Prevalence of Underweight, Stunting and Wasting Among Children in Qazvin, Iran. Iranian Journal of Pediatric Society 2010; 2: 37-43.

22. González-de Cossío T, Rivera JA, González-Castell D, UnarMunguía M, Monterrubio EA. Child malnutrition in Mexico in the last two decades: prevalence using the new WHO 2006 growth standards. Salud Publica Mex 2009; 51: S494-506. doi: 10.1590/s0036-36342009001000004

23. Sah N. Determinants of Child Malnutrition in Nepal: A Case Analysis from Dhanusha, Central Terai of Nepal. J Nepal Health Res Counc 2004; 2: 1-13.

24. Phengxay M, Ali M, Yagyu F, Soulivanh P, Kuroiwa C, Ushijima $H$. Risk factors for protein-energy malnutrition in children under 5 years: study from Luangprabang province, Laos. Pediatr Int 2007; 49: 260-5. doi: 10.1111/j.1442-200x.2007.02354.x

25. Kabubo-Mariara J, Ndenge GK, Mwabu DK. Determinants of Children's Nutritional Status in Kenya: Evidence from Demographic and Health Surveys. J Afr Econ 2009; 18: 363-87. doi: 10.1093/jae/ejn024

26. Oyekale AS. Factors Explaining Acute Malnutrition Among Under-Five Children in Sub-Sahara Africa (SSA). Life Sci J 2012; 9: 2101-7.

27. Hunter PR, MacDonald AM, Carter RC. Water Supply and Health. PLoS Med 2010; 7: e1000361. doi: 10.1371/journal. pmed.1000361

\section{Key Messages}

\section{Implications for policy makers}

- There appears a need for a surveillance system to monitoring child under-nutrition each 3-5 years.

- There need to be regional policies to control early childhood under-nutrition according to regional determinants of under-nutrition in Fars province.

- Improving knowledge and practice of mothers through appropriate programmes about childhood nutritional cares.

- Developing policies to encourage and increase the knowledge of families to take health services for child growth care especially in urban areas.

\section{Implications for public}

Our findings showed that under-nutrition prevalence in children under-six years in Fars province was in low level. Results demonstrated boys are at more risk of undernutrition relative to girls, also children resided in urban areas relative to rural, child in crowded families, and families who had low income are vulnerable to undernutrition. Moreover, maternal education at universal level is protective factor for stature growth. Khamse and Arab ethnic minorities, non-safe water supply, and non-access to health services determined as under-nutrition risk factors. So according to these determinants, children who are at risk should be monitored through healthcare system. 